\title{
Porquê ser Editor-Chefe de uma Revista Científica Médica?
}

\section{Why Become Editor-in-Chief of a Scientific Medical Journal?}

Miguel GUERRA $\square^{1,2,3}$

Acta Med Port 2019 May;32(5):330-331 - https://doi.org/10.20344/amp.12223

Palavras-chave: Políticas Editoriais; Portugal; Publicação; Revistas

Keywords: Editorial Policies; Periodicals as Topic; Portugal; Publishing

Quando em 2017, a Direção da Sociedade Portuguesa de Cirurgia Cardiotorácica e Vascular (SPCCTV) me desafiou para o cargo de editor-chefe da Revista Portuguesa de Cirurgia Cardiotorácica e Vascular (Rev Port Cir Cardiotorac Vasc) não vacilei. Aceitei prontamente com enorme orgulho, honra e (confesso!) agrado e vaidade! Que oportunidade! Que projeção!

Senti-me capaz e preparado. Tinha sido editor associado da mesma revista durante os quatro anos anteriores, conhecia os cantos à casa, sabia o que fazer e o que não fazer e certamente que seria um daqueles cargos em que o retorno é bem maior ao trabalho e tempo que nos ocupa... Que iludido e equivocado eu estava!

Editing is a big job! - A revista recebe vários artigos para revisão todas as semanas que requerem a minha atenção diária, que eu divido entre um par de horas de manhã bem cedo e antes de deitar, de forma a não interferir muito com a minha própria atividade científica e profissional, para além do familiar e social. Acompanho todo o processo de submissão juntamente com três editores associados e uma vasta lista de revisores especializados cuja generosidade que demonstram e eu testemunho ao dedicarem o seu tempo e expertise à revisão dos artigos é uma das coisas mais compensadoras em ser editor-chefe!

Editar uma revista científica é uma das contribuições mais significativas para o progresso de uma área científica, porém, e infelizmente, nem sempre é reconhecido como tal e raramente é um ponto forte quando se trata em ser promovido, avaliado num concurso ou na progressão da carreira profissional ou académica.

O trabalho é árduo e persistente! Há sempre um número prestes a sair, um em revisão e outro a ser composto a partir dos artigos entretanto submetidos e aceites. Para além disso, ser editor de uma revista muito específica (Cirurgia Cardiotorácica e Vascular) num país pequeno significa que o editor conhece pessoalmente a maioria dos autores, o que torna ainda mais difícil tomar decisões editoriais, sobretudo de rejeição!
Leio todos os manuscritos de forma a determinar se se enquadram no objetivo da revista, se a qualidade da escrita e da apresentação é adequada e se o tema é relevante e original, antes de encaminhar para revisão por pares. Isto significa algumas noitadas e fins-de-semana também, com algum engenho e perspicácia e muita subtileza e ginástica!

E tudo isto, sem ser remunerado!

Mesmo assim compensa! Voltaria a aceitar, sem hesitar e com o mesmo brio e vaidade! É uma honra ser responsável por uma publicação na minha área profissional com mais de 20 anos. É uma honra dar continuidade a um trabalho começado por nomes incontornáveis da Cirurgia Cardiotorácica e Vascular que foram os pioneiros da SPCCTV e da Rev Port Cir Cardiotorac Vasc.

Recomendo o cargo de editor. O editor está na primeira linha e tem uma vista privilegiada sobre como está a evoluir e a desenvolver-se a investigação na sua Especialidade. Mais do que isso, pode direcionar essa evolução, diligenciando edições especiais, solicitando revisões e editoriais e destacando as melhores (pelo menos para si!) tendências! Esta é outra parte muito gratificante do trabalho: ver novos campos a emergirem, capturar o registo científico e ser o primeiro leitor!

Ser editor tem seguramente as suas recompensas. ${ }^{1,2}$ Eu tive a oportunidade de interagir com os principais investigadores da minha área, tanto como autores quanto como revisores. Pude ler e confirmar novos resultados muito interessantes, mesmo antes de serem publicados! E consegui ajudar um grande número de jovens investigadores e internos a aperfeiçoar as suas publicações, tanto pelos meus próprios comentários como pelos dos revisores.

Mas ser editor-chefe não é para todos. É preciso ter disciplina, organização, paciência e thick skin. Já viram o que significa recusar um trabalho de um investigador sénior, reputado cirurgião ou até anterior mestre? Se for justificado com ciência, profissionalismo e o máximo de correção, será reconhecida a justiça da decisão e conquistado o respeito e confiança do autor.

1. Faculdade de Medicina. Universidade do Porto. Porto. Portugal.

2. Departamento de Cirurgia Cardiotorácica. Centro Hospitalar de Vila Nova de Gaia. Vila Nova de Gaia / Espinho. Portugal.

3. Editor-Chefe. Revista Portuguesa de Cirurgia Cardiotorácica e Vascular. Porto. Portugal.

$\triangle$ Autor correspondente: Miguel Guerra. migueldavidguerra@yahoo.com

Recebido: 21 de abril de 2019 - Aceite: 22 de abril de 2019 | Copyright @ Ordem dos Médicos 2019 
É uma experiência de aprendizagem inacreditável e regozijo-me por ter contribuído para o crescimento e melhoramento da nossa revista e das ciências cardiovasculares cujo futuro é auspicioso.

E que futuro antecipo para as revistas científicas? Nos primórdios, o sucesso da publicação era medido pela tiragem impressa. Supunha-se que quanto maior a tiragem, maior o número de leitores. As assinaturas e a distribuição física das revistas era, então, uma grande preocupação. Com o tempo e as inovações, as revistas científicas sofreram numerosas transformações. A revista em papel perdeu relevância e a digital tomou o seu lugar. A periodicidade deu lugar à publicação por fluxo contínuo de submissões e os leitores passaram a ter maior e mais simplificado acesso aos artigos.

Há uma dinâmica lógica da difusão virtual que precisa ser compreendida pela equipa editorial, pelos autores e pelos próprios leitores. $O$ fator de impacto, ou seja, a frequência relativa das citações de artigos, que adquiriu crescente relevância, e o acesso livre que permitiu que os investigadores publicassem os seus resultados não só para estabelecerem a sua autoria, mas também para facilitar que outros investigadores desenvolvessem novas pesquisas a partir desses resultados, alteraram por completo o novo paradigma das revistas científicas.

Assim, aumentar a visibilidade e o impacto da investigação desenvolvida, através de uma maior acessibilidade

\section{REFERÊNCIAS}

1. Fuster V. Reflections on 5 years as JACC editor-in-chief: proud of the growing family of quality. J Am Coll Cardiol. 2019;73:1866-7.

2. Lazar HL. Lessons learned from an editor-in-chief. J Card Surg 2019;34:5-6.

3. Zhi A, Husain A. Free open access medical education applications: a critical appraisal of techniques for quality assessment and content com o acesso livre, é um interesse óbvio das universidades, das suas unidades orgânicas (centros de investigação), bem como dos docentes e investigadores individualmente.

Pessoalmente, defendo a disponibilização dos resultados da investigação científica através da internet, de forma aberta, livre e sem custos para o utilizador. Contando com o apoio de investigadores, universidades e instituições de I\&D, organizações internacionais e agências públicas financiadoras de investigação, as vantagens da disponibilização de publicações em acesso aberto são amplamente reconhecidas. ${ }^{3-5}$ Estes benefícios incidem sobre a investigação de forma direta, facilitando a interdisciplinaridade e aumentando a sua visibilidade, mas também causam impacto a nível social e económico, levando a investigação a profissionais de outras áreas, a empresas e a públicos interessados.

Ninguém sabe muito bem o que vai acontecer! A publicação científica continuará por muito tempo nas mãos de grandes editoras, mas elas vão gradualmente procurar uma fórmula híbrida de publicação, pois perceberam que a questão do acesso aberto é irreversível e que a disponibilidade do corpus da literatura científica em acesso livre para todos os investigadores é também uma condição necessária para um sistema de comunicação científica que promova a eficiência e o progresso científico. Que assim seja!

discovery. Clin Exp Emerg Med. 2019;6:93-5.

4. Rabesandratana T. The world debates open-access mandates. Science. 2019;363:11-2.

5. Holbrook JB, Curry S, Kamerlin SC. Debate on academic freedom and open access is healthy. Nature. 2018;562:494. 